\title{
Experimental and Analytical Investigation of Hybrid Layer Thickness Effect on Replacing the Rebar for Reinforced Concrete Beams
}

\author{
Ola Adel Qasim ${ }^{\mathrm{a}}$, Omer Khalid Fayadh ${ }^{\mathrm{b}}$, Omar Shamal Farhan ${ }^{\mathrm{b}}$ \\ ${ }^{a}$ Civil Engineering Department, Al-Mansour University College, Baghdad, 00964, Iraq \\ E-mail: ola.adel@muc.edu.iq \\ ${ }^{b}$ Architectural Engineering Department, Al-Nahrain University, Baghdad, 00964, Iraq \\ E-mail: omerkhalid79@yahoo.com,omar.shamal@eng.nahrainuniv.edu.iq
}

\begin{abstract}
Many researchers emphasize the effectiveness of steel fiber to replace the reinforcing bar in the reinforced concrete structural elements. The fiber of different types, sizes and geometries have been added to the concrete mix with a pozzolanic material to produce Ultra-High Strength Concrete (UHSC), which has excellent properties, high strength, and durability. This paper is a lab work and theoretical study consisting of casting and testing. Twenty-one simply supported RC beams to examine the beam's behavior and the shear capacity with the full or partial depth of UHSC with or without steel fibers (UHSSFRC) for replacing the reinforcing bars. The beams were divided into five groups. Preliminary experiments tests were conducted and carried out to study hardened properties of concrete such as (compressive strength, splitting tensile strength, modulus of rupture and modulus of elasticity). The selected finite element program (ANSYS) was applied to model all tested beams. It was observed that the performance of the finite element representation gives and shows good agreement with the lab work results. The test consists of failure load, deflection, cracks and failure mode. The experimental laboratory work results showed that for $(1 \%$ steel fiber with reinforcement ratio $\rho=0.0105$ full UHSC layer) was able to give the same shear capacity for beam with (reinforcement ratio $\rho=0.0157$ regular concrete), while for $(2 \%$ steel fiber half UHSC layer and reinforcement ratio $\rho=0.0105$ ) was able to give the same ultimate shear loads of beam with (reinforcement ratio $\rho=0.0157$ normal concrete). This research reveals that the hybrid layer and steel fiber effects were able to substitute for a higher reinforcement ratio with the same shear capacity.
\end{abstract}

Keywords — Shear; Ultra-High strength concrete; hybrid; beams; steel fiber.

\section{INTRODUCTION}

The hybrid concrete concept in reinforced concrete structures is not a new idea. Composite concrete construction means the use of different concrete properties arranged in the layered system to increase the load capacity of the member [1]. Due to the advances in concrete technology, leads to composite structural element productions that possess high compressive, tensile strength, energy absorption and ductility. The process of placing many types of different concrete strengths layers at the same time so that each layer is used for its best advantages and this result leads that the concrete composite becomes a "hybrid" section. UHSC produces infinite superiority: increase flexibility, chemical resistance, freeze-thaw resistance, low creep, shrinkage, and permeability. Usually, UHSC comprise of cementitious supplementary material including a very low water ratio, these materials, which are employed both as (additives and as replacement) of cement [2]. Toward its extraordinary strength in compression and tension and durability improvement, multiplied investigator work on and attempt to compose UHSC, produced by comparable volume particles which accommodate to enhance the homogeneity of concrete and tensile strain of concrete reduction and improve the load capacity [3],[4]. Through combining (steel fiber) to develop of the concrete capability for energy-absorbing, flexibility, strength postcracking, and tensile stress endurance [5], [6]. Shear capacity of the RC beam can be improved by adding steel fibers and can be partially or totally used for replacing the stirrups or reinforcement. An attempt has been made in the present investigation to evaluate and estimate the best effective depth layer that can be able to replace and substitute the reinforcement bars by using the different hybrid layer with the impact of steel fiber ratio which is randomly distributed at different depths of the beam.

\section{A. Use of UHPC in Hybrid Elements}

Based on the concept of design criteria for the hybrid elements by using of materials with enhanced strength and 
performance, like (HSC, HPC, and UHPC), these materials are represented costly expensive [7], and should be employed for a specific layer and limited parts in the structural element, while another segment of the structure members must contain normal and traditional concrete [8]. Denarie et. al. [9] presented a lab work and theoretical study on the behavior of hybrid concrete consisting of HPFRCC and ordinary concrete beams to replace the tensile reinforcing bars by hybrid concrete layer and they concluded that these beams are much higher strength than the normal concrete beam. Wille et. al. [10] presented a lab work-study to produce UHSC concrete with a compressive strength of more than $200 \mathrm{MPa}$ without pressure or heat treatments with different variables. K. Wille et. al. [11] studied the impact of steel fiber, increasing density, fiber bonding and UHPFRC concrete on tensile strength. This research was able to reach higher tensile strength than another research. Habel et. al. [12] and Habel [13] presented a lab work on UHPFRC and normal concrete through 12 tested beams. High-performance concrete (HPC) with steel fiber was able to improve the beam behavior and reduce cracking and increase beam strength compared to normal concrete. Wang et. al. [14] presented a new UHSC with low-cost material with the influence of many variables (binder content, superplasticizer, $\mathrm{w} / \mathrm{b}$ ratio, slag and limestone) and their impact on the grade of concrete which reaches to $176 \mathrm{MPa}$ with excellent workability. Voo et. al. [15] and Kamal et. al. [16] presented a lab work research on UHPFRC concrete with the use of steel fiber comparable to steel to produce (UHSC) with raw and available and cheap materials with improvements in workability and durability and toughness. Graybeal [17], Graybeal [18] deals with impacts of materials additive and steel fiber on concrete properties to produce UHPC and define its characteristics with $150 \mathrm{MPa}$ compressive strength and $5 \mathrm{MPa}$ tensile strength and with enhanced durability. Kaiss and Mohammed [19] study the behavior of reinforced concrete beams with normal, reactive powder and hybrid concrete with different layer depths, beams final load capacity will increase by increasing layer depth and concrete strength especially in tension side. Tedepalli et al. [20] study the impact of steel fiber with different types to produce strength and ductile concrete. Additive materials and steel fiber reduce cracking and increase the toughness and improved behavior of the beam. Londhe [21] studying the impact of hooked steel fiber on beams strength under shears load. Steel fiber increased the final beam load and first cracking load and improved the deformation. Reddy et al. [22], Imran and Ahmed [23] presented non-shear reinforcement and stirrups beams with the impact of high strength materials with different steel fiber ratios. Noghabai [24] presented steel fiber for beam shear reinforcement and compared it to the normal concrete beam. They used (HSC) materials with $(98 \mathrm{MPa})$ of compressive strength and concluded that steel fiber reduces the cracking width and numbers. Voo et al. [25] used steel fiber and UHPC concrete and study their impacts on beam shear strength without stirrups, steel fiber and UHPC was able to carry shear load ultimately. Qasim [26] study the effect of fiber (steel) and UHSC on two-way slabs behavior. Foster [27] introduced fiber reinforced concrete beam and modeled it by finite element model, capable of modeling of beams falling in shear. Qasim [28] introduces the benefit of using UHSC for increasing the strength of concrete and the reduction of materials quantity by reducing the specimen's size.

\section{MATERIALS AND METHODS}

Planning of all materials and designs handled in the lab labor are introduced and discussed here:

\section{A. Cement}

ASTM Type I OPC, Ordinary Portland cement, as given in Fig. 1 implied to employ in forming each specimen, yields to the stipulations of the [1984 No.5, I.S. Designation] and followed to the [C150-89 of ASTM].
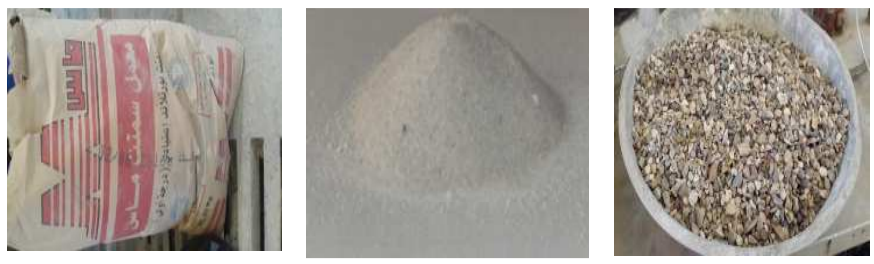

Fig. 1 Cement, fine aggregate and coarse aggregate.

\section{B. Fine Aggregate and Coarse Aggregate}

Normal fine grading sand for normal concrete mixes while for UHSC type silica sand known as glass sand was applied as presented in Fig. 1 with ( $0.74 \%$ absorption), $(0.067 \% \leq 0.5 \%$ of sulfate content), and $(2.87 \%$ of specific gravity). According to [No.882/1992 B.S. specification and No.45/1984 I.S. Iraqi specification] the fine grading is performed.

Coarse aggregate, including of maximum dimension of $10 \mathrm{~mm}$ as displayed in Fig. 1, conforms to the [I.S. Standard No.45/1984] used for regular concrete mixtures only with apparent Specific gravity $=2.47$, sulfate content $\left(\mathrm{SO}_{3}\right)$ $=0.058 \%$ and absorption $=0.52 \%$. Table 1 shows the grading of fine and coarse aggregate.

TABLE I

GRADING OF FINE AND COARSE AGGREGATE.

\begin{tabular}{|c|c|c|c|c|c|c|c|}
\hline Type & \multicolumn{2}{|c|}{ Natural Sand } & \multicolumn{2}{c|}{ Silica sand } & \multicolumn{2}{c|}{ Coarse Aggregate } \\
\hline $\begin{array}{c}\text { Sieve } \\
\text { mm }\end{array}$ & $\begin{array}{c}\text { Pass. } \\
\mathbf{\%}\end{array}$ & $\begin{array}{c}\text { I. S. } \\
\text { Limit }\end{array}$ & $\begin{array}{c}\text { Pass. } \\
\mathbf{\%}\end{array}$ & $\begin{array}{c}\text { I. S. } \\
\text { Limit }\end{array}$ & $\begin{array}{c}\text { Sieve } \\
\mathbf{m m}\end{array}$ & $\begin{array}{c}\text { Pass. } \\
\mathbf{\%}\end{array}$ & $\begin{array}{c}\text { I. S. } \\
\text { Limit }\end{array}$ \\
\hline 4.75 & 100 & $90-100$ & 100 & $95-100$ & 10 & 100 & 100 \\
\hline 2.36 & 83 & $75-100$ & 100 & $95-100$ & 4.75 & 94 & $85-100$ \\
\hline 1.18 & 70 & $55-90$ & 100 & $90-100$ & 2.36 & 16 & $0-25$ \\
\hline 0.60 & 52 & $35-59$ & 86 & $80-100$ & 1.18 & 0 & $0-5$ \\
\hline 0.30 & 21 & $8-30$ & 22 & $15-50$ & \multicolumn{4}{|c|}{} \\
\hline 0.15 & 5 & $0-10$ & 4 & $0-15$ & \multicolumn{5}{|c}{} \\
\hline
\end{tabular}

\section{Mineral Admixture and Silica Fume}

As a mineral admixture, Grey silica fume was employed by the (Basif Company for Materials) that meets the [ASTM C1240-04] for chemical and physical characteristics. It includes a highly mineral of pozzolanic activity, as shown in Fig. 2, [US Department of Transportation [29].

\section{Chemical Admixtures (Superplasticizer)}

Sika ViscoCrete-5930, an admixture with great extent water minimizing as given in Fig. 2. It possesses three abilities, retarder, modifying viscosity, and higher plasticizer which develops concrete characteristics likes, flexural, compressive, and tensile intensity can be accomplished as a 
benefit of its water-reducing characteristics as designated in [C1240-03 and C109/C109M-05 of ASTM].
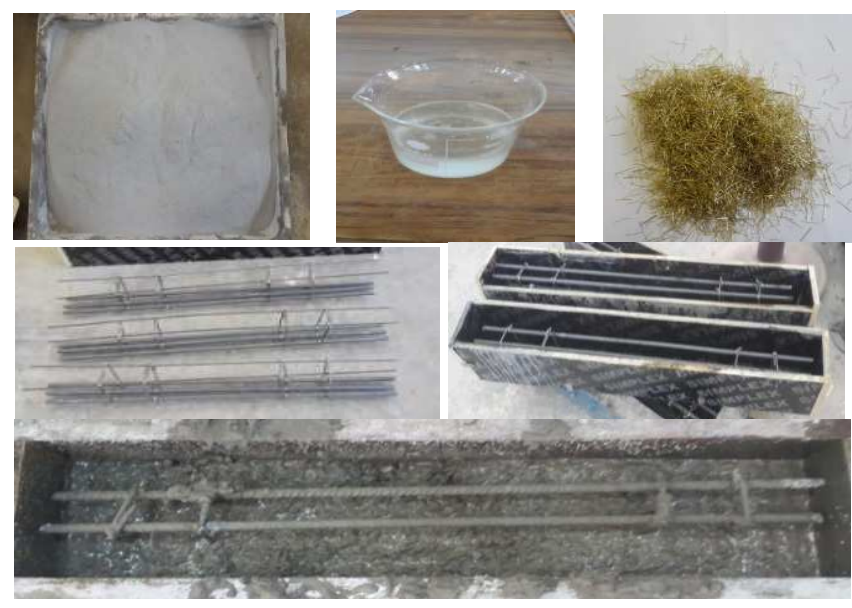

Fig. 2 Silica fume, superplasticizer, steel fiber, and steel reinforcement used

\section{E. Steel Fiber}

Fibers made of stainless steel, "round and straight design" of $(65 \mathrm{~L} / \mathrm{D})$ and $13 \mathrm{~mm}$ length with $0.2 \mathrm{~mm}$ diameter, the elastic modulus of $210 \mathrm{GPa}$, tensile strength $2600 \mathrm{MPa}$ and density of $7800 \mathrm{~kg} / \mathrm{m} 3$ as shown in Fig. 2 which conformed [ASTM A820/A 820M-04] specific requirements were used.

\section{F. Steel Reinforcement}

Three deformed steel reinforcement was used. (3 bars$\emptyset 10 \mathrm{~mm}$ with $\rho=0.0157$ ) as longitudinal reinforcement with (Ø4 $\mathrm{mm}$ as stirrup) for normal concrete beam and (2 bars$\emptyset 10 \mathrm{~mm}$ with $\rho=0.0105)$ and (2 bars- $\emptyset 8 \mathrm{~mm}$ with $\rho=0.0067)$ as longitudinal reinforcement with ( $\varnothing 4 \mathrm{~mm}$ as stirrup) were used for the hybrid beam. Two stirrups only have been used for each side of the beam, as shown in Fig. 2. A clear cover of $(20 \mathrm{~mm})$ was provided. Table 2 show the properties of steel bars used.

TABLE II

PROPERTIES OF STEEL REINFORCEMENT.

\begin{tabular}{|c|c|c|c|c|}
\hline $\begin{array}{c}\text { Bar } \\
\text { diameter } \\
(\mathbf{m m})\end{array}$ & $\begin{array}{c}\text { Area } \\
\left(\mathbf{m m}^{\mathbf{2}}\right)\end{array}$ & $\begin{array}{c}\text { Yield } \\
\text { stress } \\
(\mathbf{M P a})\end{array}$ & $\begin{array}{c}\text { maximum } \\
\text { stress } \\
(\mathbf{M P a})\end{array}$ & $\begin{array}{c}\text { Modulus of } \\
\text { Elasticity } \\
(\mathbf{G P a})\end{array}$ \\
\hline 4 & 12.56 & 517 & 601 & 200 \\
\hline 8 & 50.24 & 532 & 602 & 200 \\
\hline 10 & 78.5 & 611 & 725 & 200 \\
\hline
\end{tabular}

\section{G. Details of Lab Work}

The behavior of hybrid reinforced concrete beams that consist of two different concrete: normal concrete with the compressive strength of (31 MPa) and UHSC with different grade values for compressive strength with different depth layers are presented. The test work of this investigation comprises of casting and testing (twenty-one(21) rectangular reinforced concrete beams all with dimensions of $(100 \mathrm{~mm}$ widthx150mm heightx1000mm length), supported under two-point loading as presented in Fig. 3. One normal concrete beam with reinforcement ratio $(\rho=0.0157)$ was used as a control beam and five groups of hybrid beam with different layer thickness $(1 / 4,1 / 2,3 / 4$ and fully UHS fiber reinforced concrete) of steel fiber percentage $(0,1,2$ and $3 \%$ ) with reinforcement ratio $(\rho=0.0105$ and $\rho=0.0067)$ used to study the effective layer thickness for replacing the longitudinal steel bar. This investigation focuses on the impact of the replacement of steel reinforcement ratio with UHSSFRC of several layer depths on the shear resistance mechanism and thus the ultimate shear capacity.

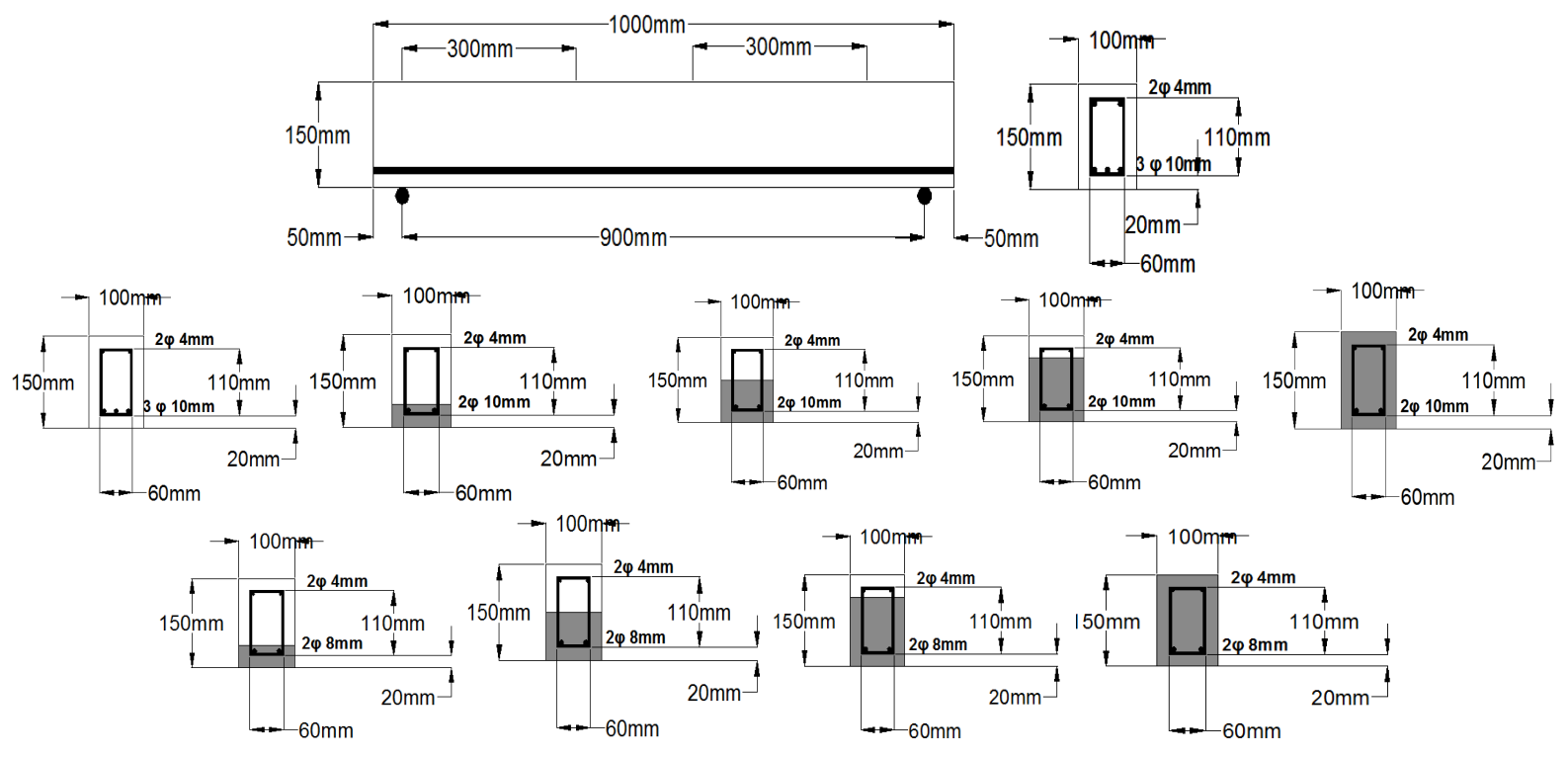

Fig. 3 Details of beam specimens, overall dimensions, reinforcement details, loading positions.

\section{H. Mix Proportions}

Two type of concrete mix was used (normal concrete and UHSC). Four steel fiber content were used (0, 1, 2 and $3 \%$ by volume). Table 3 gives mix proportions of mixes used in to cast all the beams. 
TABLE III

UHPC AND NORMAL CONCRETE MIXES DETAILS.

\begin{tabular}{|c|c|c|c|c|c|c|c|c|}
\hline Mix & Concrete type & $\begin{array}{l}\text { Cement } \\
(\mathrm{kg} / \mathrm{m} 3)\end{array}$ & $\begin{array}{c}\text { Sand } \\
(\mathrm{kg} / \mathrm{m3})\end{array}$ & $\begin{array}{l}\text { Aggregat } \\
\text { e (kg/m3) }\end{array}$ & $\begin{array}{c}\text { Silica fume by } \\
\text { weight of cement } \\
\text { (Additive) }(\%)\end{array}$ & $\begin{array}{c}\text { Superplasticizer } \\
(\%)\end{array}$ & $\mathbf{w} / \mathbf{c}$ & $\begin{array}{c}\text { Steel fiber } \\
(\%)\end{array}$ \\
\hline 1 & $\mathrm{NC}$ & 420 & 650 & 1000 & -- & --- & 0.45 & --- \\
\hline 2 & \multirow{4}{*}{ UHSC } & 975 & 1100 & -- & 25 & 6.25 & 0.2 & 0 \\
\hline 3 & & 975 & 1100 & -- & 25 & 6.25 & 0.2 & 1 \\
\hline 4 & & 975 & 1100 & -- & 25 & 6.25 & 0.2 & 2 \\
\hline 5 & & 975 & 1100 & -- & 25 & 6.25 & 0.2 & 3 \\
\hline
\end{tabular}

\section{Mixing, Casting, and Curing of Beams}

The most important start in the achievement of any research is the method of merge and mixing proportion and preparation of materials to prepare a concrete mix suitable for the implementation of the research. Wooden manufactured molds were used to match the measurements and the size required beams. Molds are joined and after completing, they are lubricated from the inside to prevent the concrete from gathering and sticking to the mold surfaces so that it can be opened easily and has a regular shape and a fair surface. The steel framework is then placed inside the mold for preparation for the casting process. In the case of the reinforced concrete beams that made from ordinary concrete, the materials were prepared in the usual manner and in the proportions as mentioned in the table of the normal concrete where the dry materials were combined together with the process of mixing gravel, sand, and cement together and add the required amount of water as it is known in the usual, in the end a homogeneous concrete mix were obtained. As for the second type of concrete mixtures, (UHSC) the fine materials were merge at the onset (cement and silica fume) to ensure their overlap. Then the third material (sand) was incorporate and merge for a registered duration of time. As a result concerning the difference in concrete mixes and because of the need for water for completing of hydration process, but in return required high strength to obtain, to compensate for the excess water used in concrete, a plasticizer is added. In order to ensure the action of the superplasticizer, the plasticizer is mixed with water and add by part. Concerning the reinforced concrete beams containing the steel fibers, the best method of mixing that prevents the gathering of fibers and also ensures the diffuse spread inside the concrete is by manual spraying. For RC beams casting with only one mixture, whether from a conventional mix or (UHSC), the concrete was mixed and then placed in the mold in two layers. To ensure complete compactness of the concrete, the first fraction was added as it was exposed to the vibrator, and then after the completion, the second fraction is added as it will undergo the same process. For beams cast with two types of concrete mixtures, two mixers were used at the same time. The first layer was poured and placed and the second layer was poured over it at the same time to ensure that the first layer was not hardening or making a joint between the two categories. Besides any mix, handle molds were provided to investigate the concrete engineering characteristics. Eventually, after the achievement of the casting process, each specimen was capped with a coating for a whole day to restrain the loss of internal water. In the following day of casting, the beams, cubes, prism, and cylinders were unfastened and placed in laboratory curing tanks in the lab to continue processed for 27 days. All specimens were removed from the curing and kept dry earlier than the arrangement of evaluation. Fig. 4 shows preparation, mixing, casting and curing procedure.
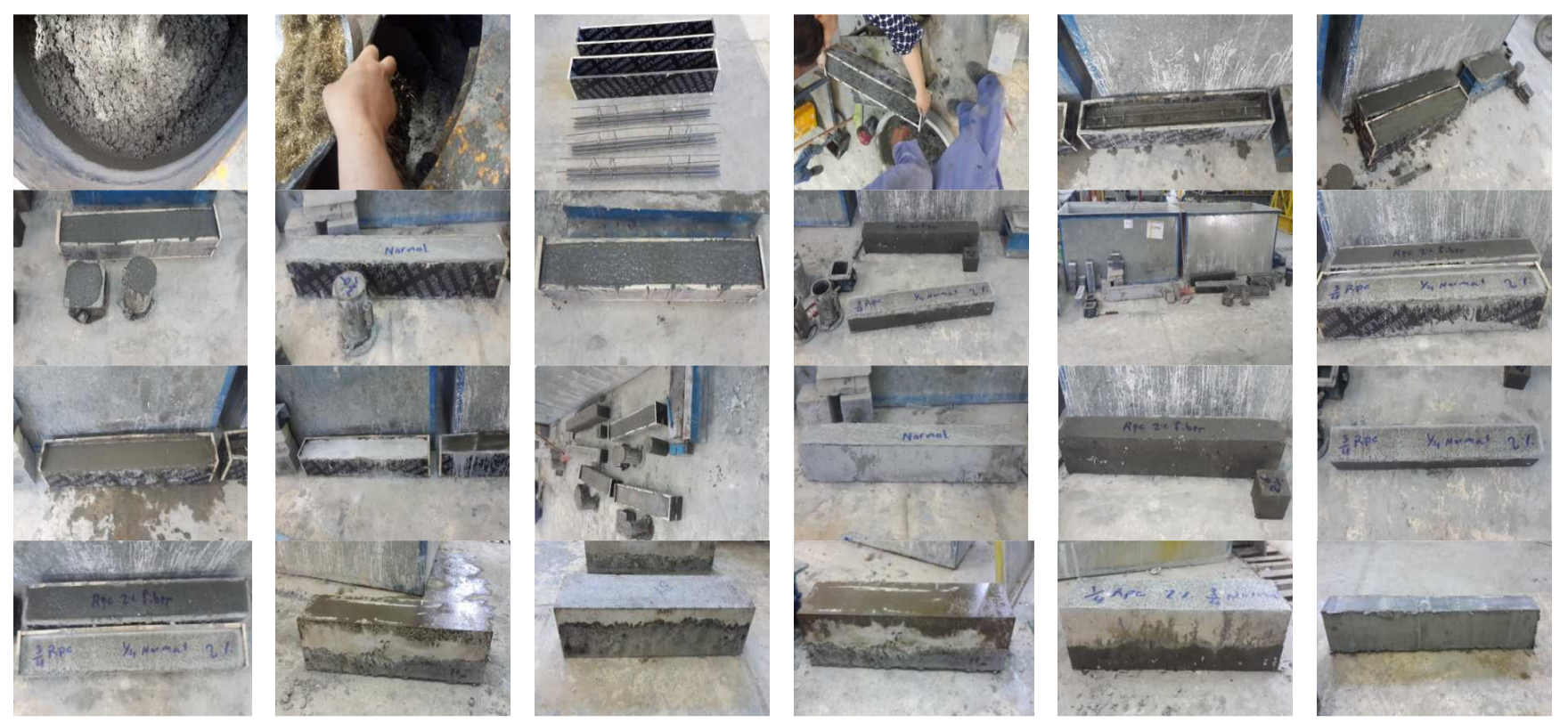

Fig. 4 Preparation, mixing, casting and curing procedure. 


\section{RESULTS AND DISCUSSION}

Details of all hardened concrete tests used in the lab work are presented and discussed:

\section{A. Mechanical Properties of Hardened Concrete (Compressive Strength Test)}

Table 4 shows the hardening properties details of mixes used in the present research. The 28-days of strength was planned relating to [C39-2005 of ASTM] and [part 116 of B.S-1881]. (specimens of $100 \times 200 \mathrm{~mm}$ cylindrical mold were employed and prepare to obtain compressive strength operating a hydraulic universal digital compression testing device (ELE-Digital Elect 2000) of $2000 \mathrm{kN}$ capacity. Fig. 5 show concrete mix type and increase in compressive strength with steel fiber impact. During steel fiber advancement from $(0,1,2$, and $3 \%)$ an improvement were achieved of about $(0$, $24.39,43.9$, and $58.53 \%$ ) in average compressive strength.

\section{B. Mechanical Properties of Hardened Concrete (Flexural Strength Test)}

The test of flexural strength at 28-day age was performed according to [ASTM C348-02] on prismatic specimens of $(70 \times 70 \times 280 \mathrm{~mm})$ using a two-force instrument machine (ELE) to represents the concentrated loading. The significant joining of steel fibers to the combination will provide uncommon features and extend durability. This behaviour is related to refinement in the size and grain of the pores operation whom whose strengthens the region of transformation and defeat minor-cracking (micro) in the mediator. Fig. 6 shows concrete mix type and increasing in

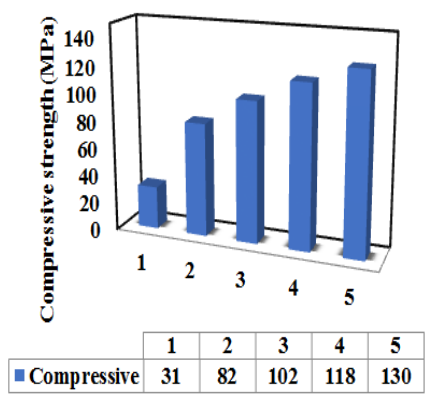

Fig. 5 Concrete mix type and increase in compressive strength with steel fiber impact.

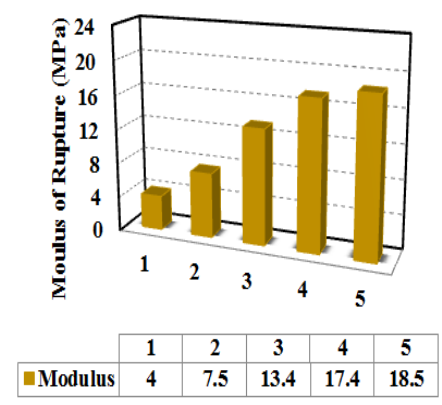

Fig. 6 Concrete mix type and increase in flexural strength with steel fiber impact.

flexural strength with steel fiber impact. During steel fiber raises of $(0,1,2$, and $3 \%)$ an increase in flexural strength of about $(0,78.66,132$, and $146.66 \%)$ was presented.

\section{Mechanical Properties of Hardened Concrete (Splitting Tensile Strength Test)}

Tensile test at 28-day age was handled on (diameter of $100 \mathrm{~mm} \times$ height of $200 \mathrm{~mm}$ cylinders mold). The operation was achieve out in conformity with [C496-04 of ASTM designation] and operations were performed to make use of (ELE-Digital Elect 2000) device. When steel fiber raises from $(0,1,2$, and $3 \%)$ an increase were achieved in an average of tensile splitting strength of about $(0,78.57$, 122.85 and $142.85 \%$ ). In both the hardened and throughout the hardening state; fibers enhance the matrices features of cement-based, they are proficient in arrest crack extension and transport stresses over a crack within bridging the cracks. Fig. 7 show concrete mix type and increase in splitting tensile strength with steel fiber impact

\section{Mechanical Properties of Hardened Concrete (Modulus of Elasticity)}

Examination with cylinders of $(100 \mathrm{~mm} \times 200 \mathrm{~mm})$ performed according to [ASTM C469-02] to compute and calculate the modulus of elasticity of concrete. Fig. 8 shows concrete mix type and increase in modulus of elasticity with steel fiber impact. Fig. 9 shows the hardened concrete tests for (compressive strength, splitting tensile strength, flexural strength, and modulus of the elasticity test).

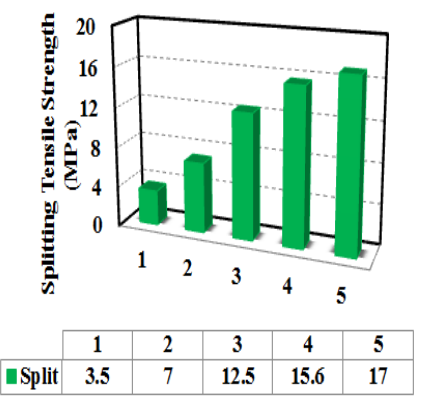

Fig. 7 Concrete mix type and increase in splitting tensile strength with steel fiber impact.

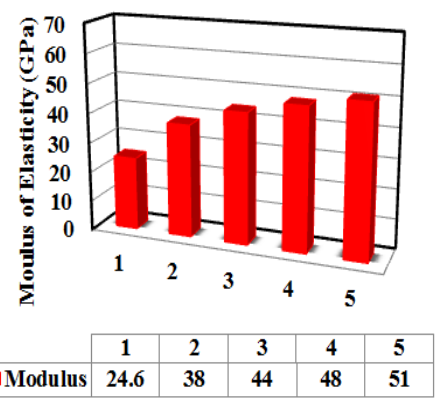

Fig. 8 Concrete mix type and increase in modulus of elasticity with steel fiber impact.

TABLE IV

PROPERTIES OF HARDENED CONCRETE AND INCREASING PERCENTAGE.

\begin{tabular}{|c|c|c|c|c|c|c|c|c|c|}
\hline $\begin{array}{c}\text { specimens } \\
\text { Designation }\end{array}$ & $\begin{array}{l}\text { Vf } \\
\%\end{array}$ & $\begin{array}{c}\text { Compressive } \\
\text { Strength } \\
\mathbf{f}^{\prime}{ }_{\mathbf{c}}(\mathbf{M P a})\end{array}$ & $\begin{array}{c}\text { Percentage } \\
\text { Increase } \\
\mathbf{f}_{\mathbf{c}}^{\prime}(\%)\end{array}$ & $\begin{array}{c}\text { Splitting } \\
\text { Tensile } \\
\text { Strength } \\
\mathbf{f}_{\mathrm{t}}(\mathbf{M P a})\end{array}$ & $\begin{array}{c}\text { Percentage } \\
\text { Increase in } \\
\text { ft }(\%)\end{array}$ & $\begin{array}{l}\text { Flexural } \\
\text { strength } \\
\mathbf{f}_{\mathbf{r}}(\mathbf{M P a})\end{array}$ & $\begin{array}{c}\text { Percentage } \\
\text { Increase in } \\
\mathbf{f}_{\mathbf{r}} \\
(\%)\end{array}$ & $\begin{array}{c}\text { Modulus } \\
\text { of } \\
\text { Elasticity } \\
\mathbf{E}_{\mathbf{c}}(\mathbf{G P a}) \\
\end{array}$ & $\begin{array}{c}\text { Percentage } \\
\text { Increase in } \\
\mathrm{E}_{\mathrm{c}}(\%)\end{array}$ \\
\hline Mix 1 & 0 & 31 & --- & 3.5 & --- & 4 & -- & 24.6 & -- \\
\hline Mix 2 & 0 & 82 & 0 & 7 & 0 & 7.5 & 0 & 38 & 0 \\
\hline Mix 3 & 1 & 102 & 24.39 & 12.5 & 78.57 & 13.4 & 78.66 & 44 & 15.78 \\
\hline Mix 4 & 2 & 118 & 43.90 & 15.6 & 122.85 & 17.4 & 132 & 48 & 26.31 \\
\hline Mix 5 & 3 & 130 & 58.53 & 17 & 142.85 & 18.5 & 146.66 & 51 & 34.21 \\
\hline
\end{tabular}




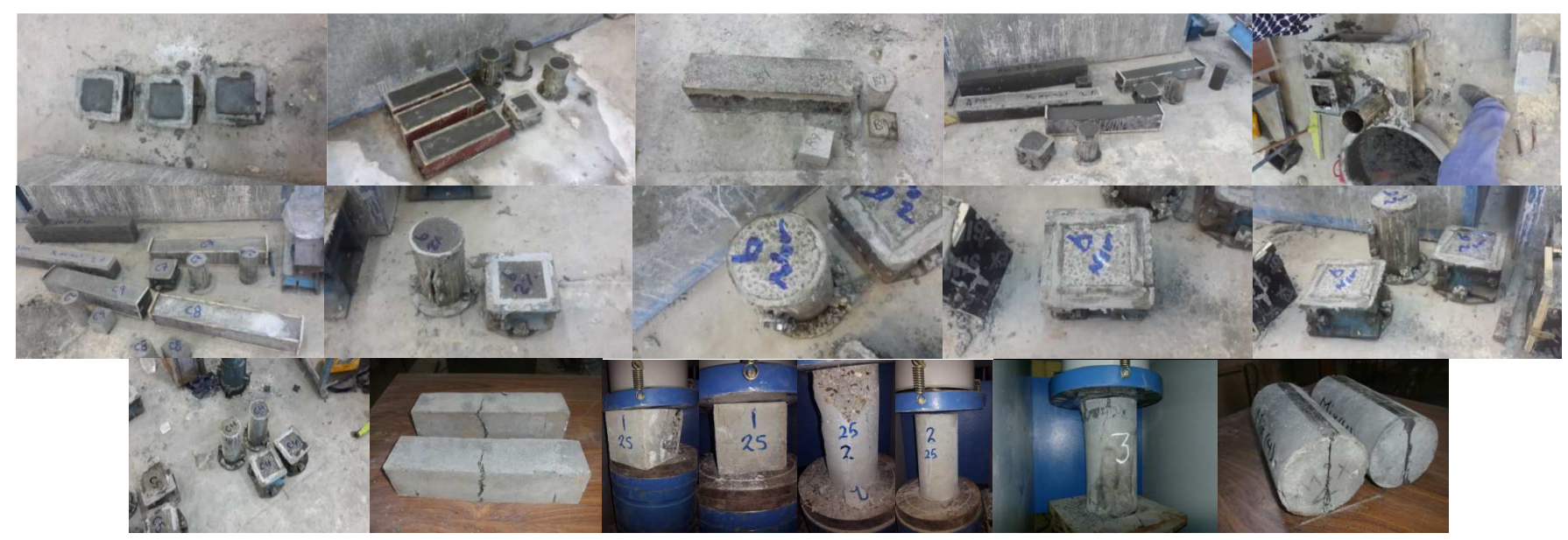

Fig. 9 Hardened Concrete Tests.

\section{E. Testing of Beams and Mode of Failure}

After removing the beam from water tank, the beam is set by cleaning, consequently the cracks will be regularly recognized. The tested beams are supported and loaded with a load of two points. Beams were tested at age (28) days. The beam sample held and placed on the test machine and stabilized, and then loading from machine steps was utilized slowly in successive increments. Through the completion of individually load increasing increment, perception and mensuration were reported electrically by the loading device machine and the development of the cracks and cracks propagation were marked on the beam surface. The developments of the cracks have been marked in each load increase. The testing process was monitored on the computer screen, and all load and deformations data were recorded. The failure mode as expected, was a typical shear failure in all tested beams. Shear cracks are generally formed in concrete beams in regions where shear force exceeds the strength of the concrete (where shear stress exceeds the concrete shear stress capacity). Fig. 10 shows photographs of the shear failure and crack propagations after the failure of the tested beams.

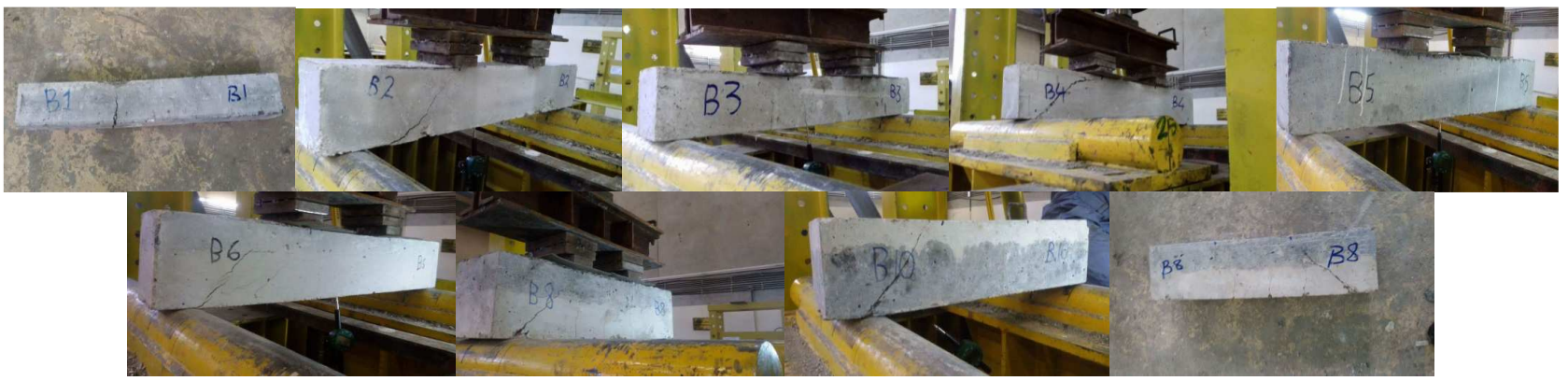

Fig. 10 Shear failure and crack propagations of the tested beams

\section{F. Nonlinear Finite Element Analysis of RC Beams by (ANSYS)}

The performance of RC beams with UHPC layer with steel fiber was analyzed and investigated by Finite Element Analysis software ANSYS. Analysis by finite element is a numerical technique popularly employed to the concrete constructions based on the application of the nonlinear performance of the material. It can be adapted to predict the performance of beam structure at the elastic stage, plastic stage, cracking load, post-cracking stage, and maximum load [30], [31]. The finite element patterns used in the current study was explained by using the ANSYS program for the materials description and the structural members. SOLID65 element assembles the reinforced concrete beams. This element can consider tension cracking, compression crushing, and plastic deformation which is characterized by eight nodes possessing at every node three degrees of freedom implying a translation in the $\mathrm{x}, \mathrm{y}$, and $\mathrm{z}$-direction. The reinforcement bars modeled using an element described
LINK8 as displayed in Fig. 11. This element is a 3-D spar and uniaxial tension-compression element with three degrees of freedom at all nodes and is appropriated to be smeared throughout the solid element. The intention of this examination was to generate a numerical model where material with nonlinear properties of beams with hybrid concrete layers can be incorporated into specific analyses. The results received explained a good compromise with those achieved by a lab work program. The results of this investigation indicated that it is reasonable to predict the performance of beams with a hybrid layer using FEA without the requirement for costly lab work testing [32], [33].

\section{G. Concrete Materials Properties}

Concrete is a material with brittle properties that have two different behaviors cases. In compression state, concrete has many stress-strain curves which depend on the grade and the type of concrete. In the program, the stress-strain curve is introduced using lab work test results where the drawing of 
the relationship between the stress and strain will be represented by a multi-linear isotropic curve, designating linearly up to $40 \%$ of total concrete strength. To insert the curve into the program it is divided into 6 points connected by straight lines to describe the relationship between the lab work stress-strain concrete as given in Fig. 12.

\section{H. Tension Behavior of Concrete (Behavior of steel fiber reinforced concrete)}

The linear elastic model is usually used before cracking to simulate concrete behavior in tension. In general, the standard for cracking concrete is expressed in terms of tensile stress or major strains. In this research, the crack beginning is controlled by a maximum stress criterion. A smeared crack model was adopted with fixed perpendicular cracks to represent fractured concrete. Normal to the crack plane the tensile stresses are released and gradually represented by the average stress-strain curve. For such a relationship, stress-relieving or stress-relieving concepts can be used. In this work, the concept of the tension-stiffening model been adopted. Since the fractured concrete still initially tolerates some tensile stresses in a perpendicular direction to crack. This has been adopted in ANSYS by assuming the gradual release of a concrete stress component perpendicular to the cracked plane. Two models were used to account for tension-stiffening impact as shown in Fig. 13. The model designated TS1 is suitable for analyzing reinforced concrete beams without fibers, while model TS2 is suitable for analyzing fiber reinforced concrete beams. The finite element solutions show that the load-deflection response of the tested beams obtained using model TS2 is close to lab work load-deflection responses and the predicted maximum loads are close to the actual lab work failure loads [32], [33]. In nonlinear finite element analysis by ANSYS, the values of coefficients used in the opening $(\beta \mathrm{t})$ is equal to 0.2 and closing $(\beta c)$ is equal to 0.7 .
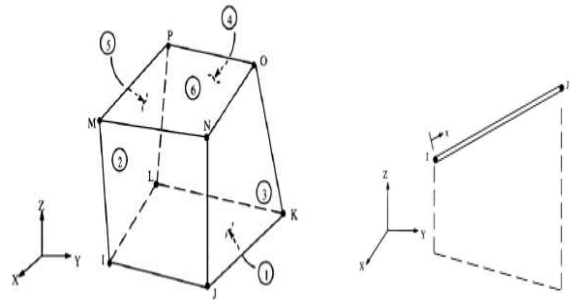

Fig. 11 Concrete and Steel Solid 65 and 3D-LINK 8. [30], [31]

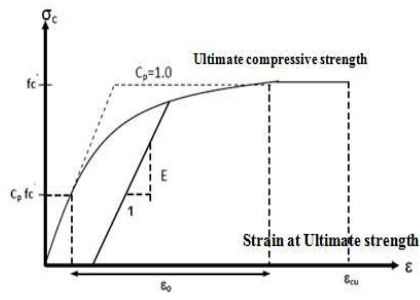

Fig.12 Concrete uniaxial compression stress-strain curve. [30],[31]

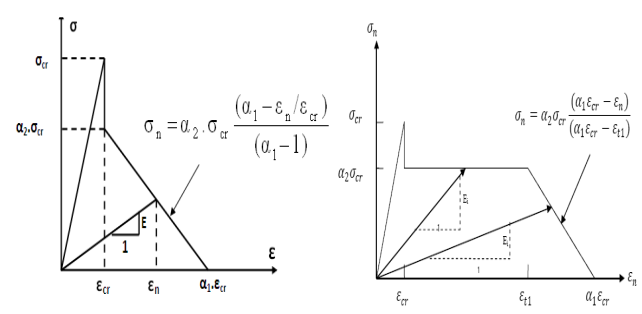

Fig. 13 Post-cracking model of conventionally reinforced concrete (TS1) and steel fiber concrete (TS2). [32]-[33]

\section{Maximum Loads and Load-Deflection}

The lab work test consists of investigating the mode of failure and crack pattern, maximum load, and deflection. It was observed that due to the application of hybrid with steel fiber layer at a different depth level of the beams, shear failure mode occurred in those specimens. The final load's results of the measured beams are recorded in Table 4 . In the implemented experimental investigation, the diagonal failure took place in whole examined beams. Shear failures in beams are produced by the diagonal cracks near the support and beams fail directly simultaneously with the development of these cracks in the region with high-shear whenever the shear force passes the strength of the concrete, or the amount of actual shear stress exceeds the allowable concrete shear stress. The addition of steel fiber influences the initial diagonal cracking load and improved the ultimate load capacity. The maximum shear load of all the tested beams is presented in Figs. 14-18. The results commonly reveal that the maximum loads develop and improved with the increase of UHSC layer thickness and the steel fibers volumetric ratio (Vf).

\section{J. Impact of Ultra-High Strength Layer Thickness}

The ultimate deflection and loads are advanced when the steel fiber content is raised. Higher deflection at fracture related to larger fiber contents. Beams with fibers manifested extremely more limited corruption at fracture than without fibers beams. The steel fibers turn to be a productive following load of first cracking and proceed to maintain the principal stresses of tensile continuously until at one critical crack the entire of all fibers pullout happens. The maximum load of all the tested beams is shown in Figs. 19-22.

- For beam of $(0 \%$ steel fiber $)$ with $(\rho=0.0105)$ and layer with [(0.75 normal concrete with 0.25 UHSC), [(0.5 normal concrete with 0.5 UHSC), (0.25 normal concrete with 0.75 UHSC) and (full UHSC)] there is a decreasing in the maximum shear load compared to the normal concrete beam with $(\rho=0.0157)$ of about $(25.20,23.44,21.68$ and $12.0 \%)$ that mean this layers cannot be able to replace the reinforcement ratio of $(\rho=0.0157)$.

- For beam of $(1.0 \%$ steel fiber $)$ with $(\rho=0.0105)$ and layer with [(0.75 normal concrete with 0.25 UHSC), (0.5 normal concrete with 0.5 UHSC) and (0.25 normal concrete with 0.75 UHSC)] there is a decreasing in the maximum shear load compared to the normal concrete beam of with $(\rho=0.0157)$ of about $(12.91,9.91$ and $7.91 \%)$ that means this layer cannot be able to replace the reinforcement ratio of $(\rho=0.0157)$. However, for the same reinforcement ratio $(\rho=0.0105)$ and the same steel fiber ratio with (full UHSC) layer, there is increasing in the maximum shear load of about $(0.1 \%)$ which means this layer can be able to replace the reinforcement ratio $(\rho=0.0157)$.

- For beam of $(2.0 \%$ steel fiber $)$ with $(\rho=0.0105)$ and layer with $[(0.75$ normal concrete with 0.25 UHSC) there is a decreasing in the maximum shear load with normal concrete beam with $(\rho=0.0157)$ of about 
$(2.8 \%)$ that means this layer cannot be able to replace the reinforcement ratio of $(\rho=0.0157)$. But for the same reinforcement ratio $(\rho=0.0105)$ and same steel fiber ratio with [( 0.5 normal concrete with 0.5 UHSC), (0.25 normal concrete with 0.75 UHSC) and (full UHSC) layer there is increasing in the maximum shear load of about $(0.44,2.6$ and $8.0 \%)$ that mean this layers can be able to replace the reinforcement ratio of $(\rho=0.0157)$.

- For beam of $(3.0 \%$ steel fiber $)$ with $(\rho=0.0105)$ and layer with [(0.75 normal concrete with 0.25 UHSC), [(0.5 normal concrete with 0.5 UHSC), (0.25 normal concrete with 0.75 UHSC) and (full UHSC)] there is increasing in the maximum shear load with normal concrete beam with $(\rho=0.0157)$ of about $(4.88,8.3$, 10.58 and $14.0 \%$ ) that means this layers can be able to replace the reinforcement ratio of $(\rho=0.0157)$.

\section{$K$. Impact of $(\rho)$ Longitudinal Steel Ratio}

Figures from 23-26 presented the maximum shear load with the effects of $(\rho)$ steel ratio of the tested beams. For beam of $(2.0 \%$ steel fiber) with $(\rho=0.0105)$ and layer with [(0.75 normal concrete with 0.25 UHSC), [ 0.5 normal concrete with 0.5 UHSC), (0.25 normal concrete with 0.75 UHSC) and (full UHSC)] there is a decreasing in the maximum shear load with normal concrete beam with $(\rho=0.0157)$ of about $(7.54,4.53,2.51$ and $0.5 \%)$ that means this layers cannot be able to replace the reinforcement ratio of $(\rho=0.0157)$.

\section{Modeling of Beams, Meshing, Loads and Boundary Conditions}

To guarantee that the design model operates the identical process as the lab work examination, boundary conditions require applying wherever the support and loadings are determined. A full-beam was adopted to model it in finite element program. Square or rectangular mesh elements were formulated for ideal and closest results. The lab work model form was apportioned into a fraction of small objects. Deformations and stresses were computed at the integration points of these small items after loading. The externally utilized load was expressed by the duplicate nodal forces about the uppermost contract node at the element surface. To get an uncommon solution, boundary conditions for the displacement are required to apply to restrict the model. Loads have been implemented to failure gradually as demand by the Newton-Raphson operation. Thence, the overall utilized load was separated into a progression of load increments. In certain stages of the analysis, the size of the load step varies from large to small. In all circumstances, the convergence of the solution was fulfilled before the program reaches the maximum iteration. Failure is established for every model when the solution does not converge with the minimum load increment. The deflection and stresses the contour of the selected element of the analysis beam due to loading employed as indicated in Fig. 27. Figures 28-48 and Table 4 displays the comparison between the final loads of the experimentally tested beam and the finite element. As mentioned earlier, the principal objectives of this investigation are to investigate the efficacy of the hybrid layers to substitute the steel reinforcement and the influence of the steel fibers on the shear performance of $\mathrm{RC}$ concrete beams. Throughout the lab work, the maximum loads, cracking load and the shear load were registered versus the deflection. Verification is made for the efficiency and validity of the finite element system. The correctness of the selected models is managed by guaranteeing that the failure modes are accurate and that the final load is moderately predicted associated with the lab work conclusion. The overall behavior of finite element models was determined to be adequately correlated with lab work test results between (87\% to $95 \%)$.

TABLE V

LAB WORK AND FINITE ELEMENT RESULTS OF THE TESTED BEAM.

\begin{tabular}{|c|c|c|c|c|c|c|c|c|}
\hline $\begin{array}{c}\text { Beam } \\
\text { No. }\end{array}$ & Beam Type & Reinforcement ratio & Fiber $(\%)$ & $\mathbf{f}_{\mathrm{c}}^{\prime}(\mathbf{M P a})$ & $\begin{array}{c}\text { Lab work Vu } \\
\text { Load }(k N)\end{array}$ & $\begin{array}{l}\text { Impact of steel fiber } \\
\text { and layer thickness } \\
\text { with normal concrete }\end{array}$ & $\begin{array}{l}\text { FEM Load } \\
(\mathbf{k N})\end{array}$ & $\begin{array}{c}\text { FEM/EXP } \\
(\%)\end{array}$ \\
\hline 1 & Normal & $\begin{array}{l}3 \varphi 10 \mathrm{~mm} \\
\rho=0.0157\end{array}$ & $0 \%$ fiber & 31 & 68.97 & $0.00 \%$ & 64.82 & 93.98 \\
\hline 2 & $\begin{array}{c}0.75 \text { Normal } \\
0.25 \text { UHSC }\end{array}$ & \multirow{4}{*}{$\begin{array}{l}2 \varphi 10 \mathrm{~mm} \\
\rho=0.0105\end{array}$} & \multirow{4}{*}{$0 \%$ fiber } & \multirow{4}{*}{86} & 51.59 & $-25.20 \%$ & 47.46 & 91.99 \\
\hline 3 & $\begin{array}{c}0.5 \text { Normal } \\
0.5 \text { UHSC } \\
\end{array}$ & & & & 52.80 & $-23.44 \%$ & 49.10 & 92.99 \\
\hline 4 & $\begin{array}{c}0.25 \text { Normal } \\
0.75 \text { UHSC }\end{array}$ & & & & 54.02 & $-21.68 \%$ & 49.69 & 91.98 \\
\hline 5 & UHSC & & & & 60.69 & $-12.00 \%$ & 56.44 & 93.00 \\
\hline 6 & $\begin{array}{c}\text { 0.75 Normal } \\
0.25 \text { UHSC }\end{array}$ & \multirow{4}{*}{$\begin{array}{l}2 \varphi 10 \mathrm{~mm} \\
\rho=0.0105\end{array}$} & \multirow{4}{*}{$1 \%$ fiber } & \multirow{4}{*}{102} & 60.00 & $-12.91 \%$ & 57.00 & 95.00 \\
\hline 7 & $\begin{array}{c}0.5 \text { Normal } \\
0.5 \text { UHSC } \\
\end{array}$ & & & & 62.07 & $-9.91 \%$ & 55.24 & 89.00 \\
\hline 8 & $\begin{array}{c}\text { 0.25 Normal } \\
0.75 \text { UHSC }\end{array}$ & & & & 63.45 & $-7.91 \%$ & 55.83 & 87.99 \\
\hline 9 & UHSC & & & & 68.97 & $0.10 \%$ & 62.75 & 90.98 \\
\hline 10 & $\begin{array}{c}\text { 0.75 Normal } \\
0.25 \text { UHSC }\end{array}$ & \multirow{4}{*}{$\begin{array}{l}2 \varphi 10 \mathrm{~mm} \\
\rho=0.0105\end{array}$} & \multirow{4}{*}{$2 \%$ fiber } & \multirow{4}{*}{118} & 67.04 & $-2.80 \%$ & 63.01 & 93.99 \\
\hline 11 & \begin{tabular}{|c|}
0.5 Normal \\
0.5 UHSC \\
\end{tabular} & & & & 69.27 & $0.44 \%$ & 65.80 & 94.99 \\
\hline 12 & $\begin{array}{c}0.25 \text { Normal } \\
0.75 \text { UHSC }\end{array}$ & & & & 70.76 & $2.60 \%$ & 62.97 & 88.99 \\
\hline 13 & UHSC & & & & 74.48 & $8.00 \%$ & 70.01 & 94.00 \\
\hline
\end{tabular}




\begin{tabular}{|c|c|c|c|c|c|c|c|c|}
\hline 14 & 0.75 Normal & \multirow{6}{*}{$\begin{array}{l}2 \varphi 10 \mathrm{~mm} \\
\rho=0.0105\end{array}$} & \multirow{6}{*}{$3 \%$ fiber } & \multirow{6}{*}{130} & 72.33 & $4.88 \%$ & 66.54 & 9200 \\
\hline \multirow{3}{*}{15} & 0.25 UHSC & & & & & \multirow{2}{*}{$8.30 \%$} & & \\
\hline & 0.5 Normal & & & & 74.69 & & 69.46 & 93.00 \\
\hline & $\begin{array}{c}0.5 \text { UHSC } \\
0.25 \text { Normal }\end{array}$ & & & & & & & \\
\hline 16 & 0.75 UHSC & & & & 76.26 & $10.58 \%$ & 69.39 & 90.99 \\
\hline 17 & UHSC & & & & 78.62 & $14.00 \%$ & 74.68 & 94.99 \\
\hline 18 & 0.75 Normal & \multirow{6}{*}{$\begin{array}{c}2 \varphi 8 \mathrm{~mm} \\
\rho=0.0067\end{array}$} & \multirow{6}{*}{$2 \%$ fiber } & \multirow{6}{*}{118} & \multirow{2}{*}{63.45} & \multirow{2}{*}{$-7.54 \%$} & \multirow{2}{*}{59.00} & \multirow{2}{*}{92.99} \\
\hline & 0.25 UHSC & & & & & & & \\
\hline \multirow{2}{*}{19} & 0.5 Normal & & & & \multirow{2}{*}{65.52} & \multirow{2}{*}{$-4.53 \%$} & \multirow{2}{*}{60.27} & 91.99 \\
\hline & 0.5 UHSC & & & & & & & \\
\hline 20 & $\begin{array}{c}0.25 \text { Normal } \\
0.75\end{array}$ & & & & 66.90 & $-2.51 \%$ & 59.64 & 89.15 \\
\hline 21 & UHSC & & & & 68.97 & $-0.50 \%$ & 62.75 & 90.98 \\
\hline
\end{tabular}
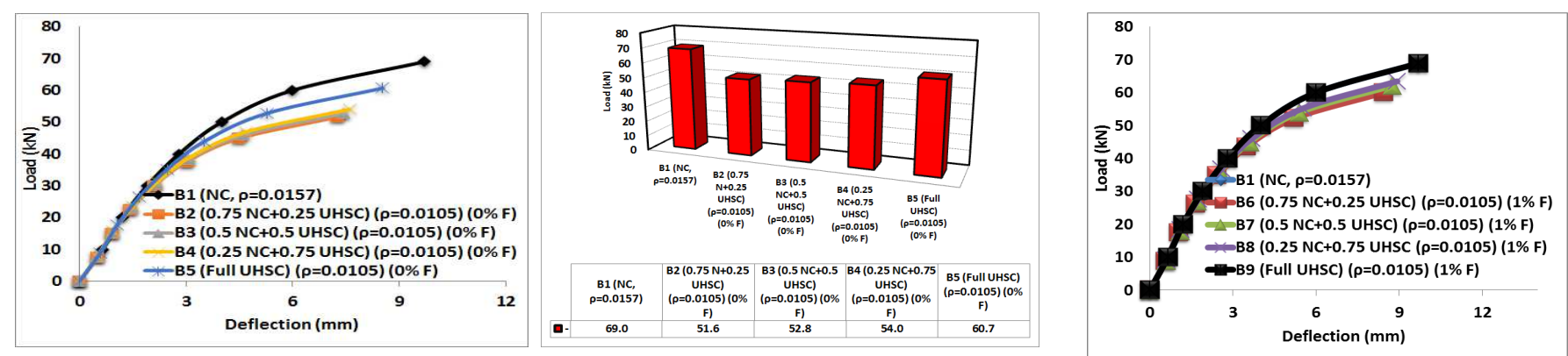

Fig. 14 Load-deflection curve for hybrid concrete beam (1,2,3,4 and 5) with steel fiber (0\%)

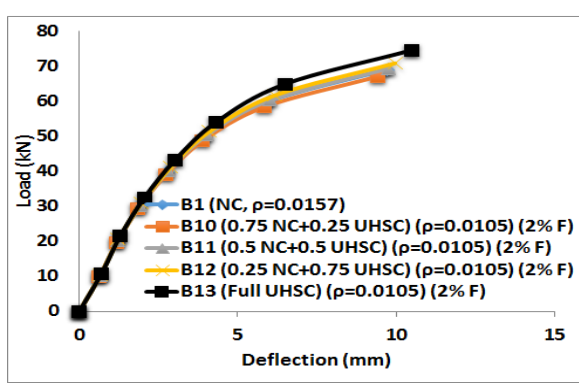

Fig. 16 Load-deflection curve for hybrid concrete beam $(1,10,11,12$ and 13$)$ with steel fiber $(2.0 \%)$

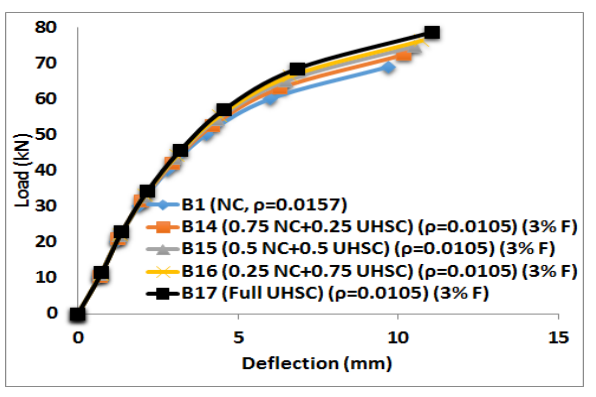

Fig. 17 Load-deflection curve for hybrid concrete beam $(1,14,15,16$ and 17$)$ with steel fiber $(2.0 \%)$
Fig. 15 Load-deflection curve for hybrid concrete beam $(1,6,7,8$ and 9$)$ with steel fiber $(1.0 \%)$

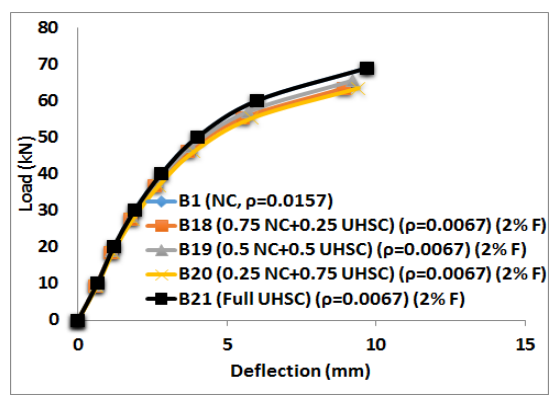

Fig. 18 Load-deflection curve for hybrid concrete beam $(1,18,19,20$ and 21$)$ with steel fiber $(3.0 \%)$

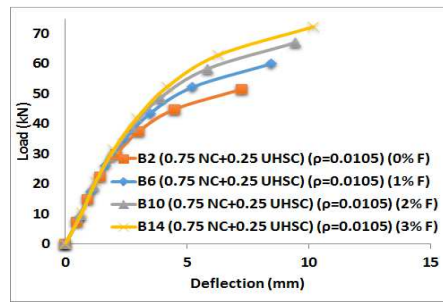

Fig. 19 Impact of layer thickness on the load-deflection curve for hybrid beam $(2,6,10$ and 14$)$ with $(0.75$ normal concrete and 0.25 UHSC).

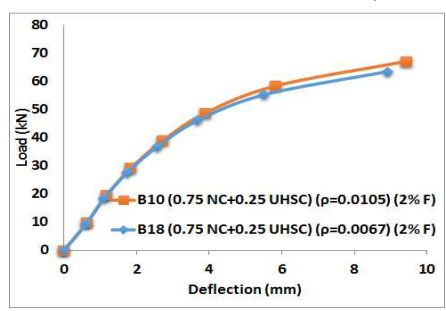

Fig. 23 Impact of steel ratio on the load-deflection curve for hybrid beam (10 and 18) with SF (2.0\%).

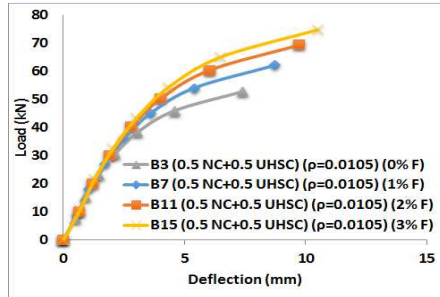

Fig. 20 Impact of layer thickness on the load-deflection curve for hybrid beam $(3,7,11$ and 15$)$ with $(0.5$ normal concrete and 0.5 UHSC).

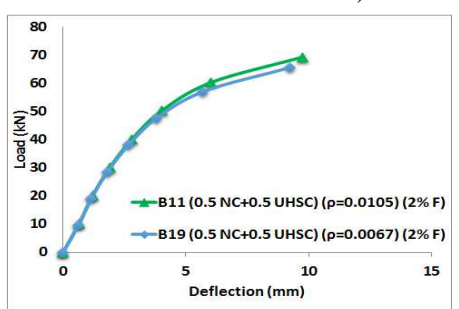

Fig.24 Impact of steel ratio on the load-deflection curve for hybrid beam (11 and 19) with SF (2.0\%).

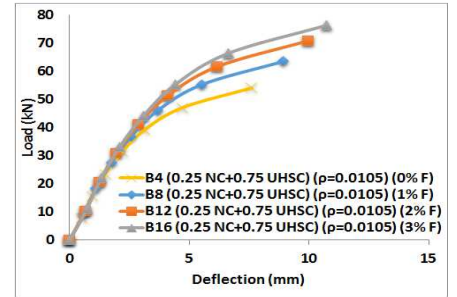

Fig. 21 Impact of layer thickness on the load-deflection curve for hybrid beam $(4,8,12$ and 16$)$ with $(0.25$ normal concrete and 0.75 UHSC).

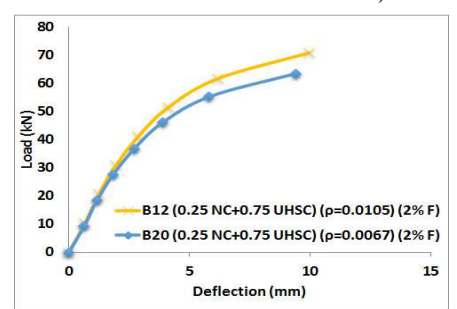

Fig. 25 Impact of steel ratio on the load-deflection curve for hybrid beam (12 and 20) with SF (2.0\%).

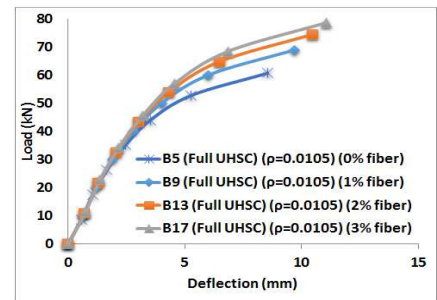

Fig. 22 Impact of layer thickness on the load-deflection curve for hybrid beam $(5,9,13$ and 17) with (full UHSC).

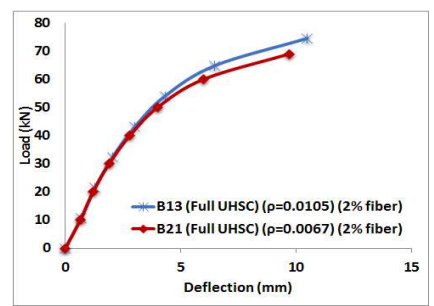

Fig. 26 Impact of steel ratio on the load-deflection curve for hybrid beam (13 and 21) with SF (2.0\%). 

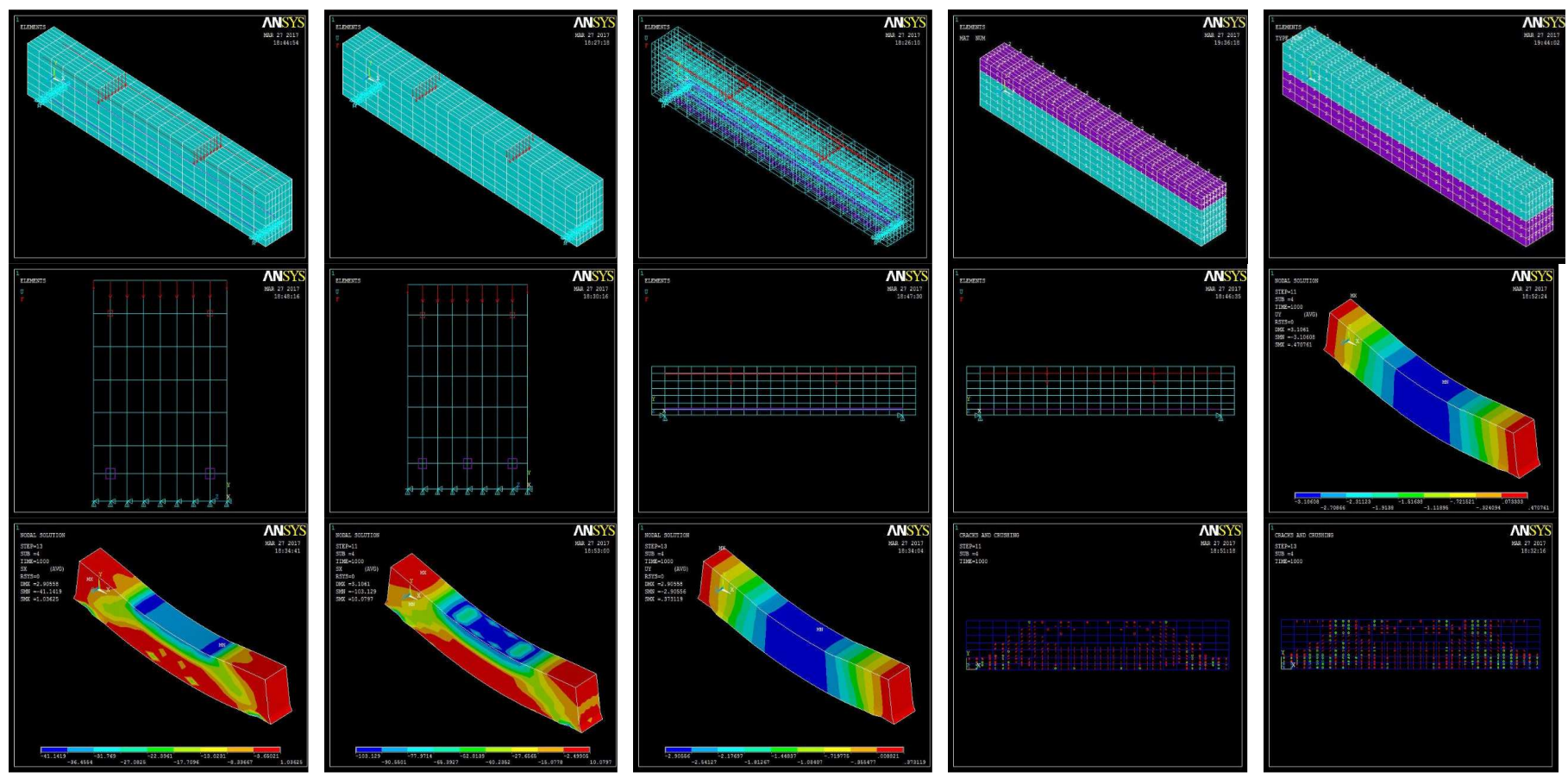

Fig. 27 Finite element meshing, boundary condition, loading arrangement, crack and stress contour.

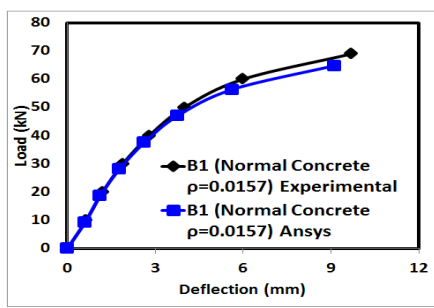

Fig. 28 Exp. and Ansys loaddeflection curve beam (1).

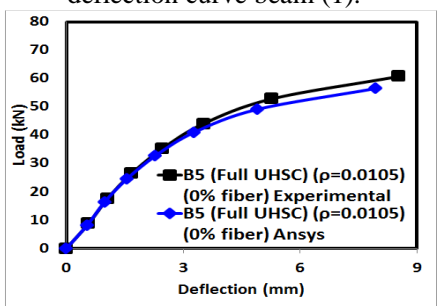

Fig. 32 Exp. and Ansys loaddeflection curve beam (5).

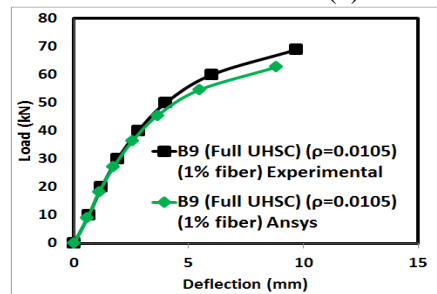

Fig. 36 Exp. and Ansys loaddeflection curve beam (9).

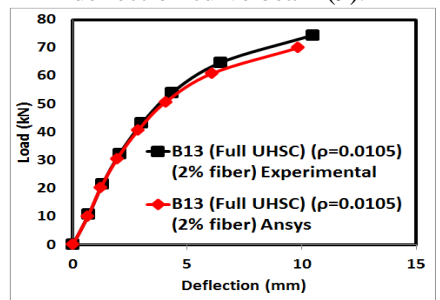

Fig. 40 Exp. and Ansys loaddeflection curve beam (13).

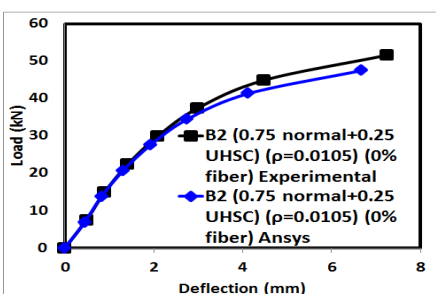

Fig. 29 Exp. and Ansys loaddeflection curve beam (2).

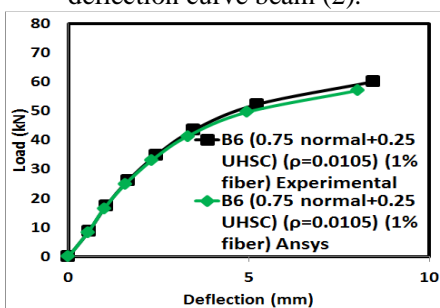

Fig. 33 Exp. and Ansys loaddeflection curve beam (6).

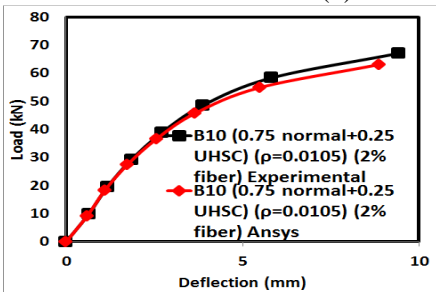

Fig. 37 Exp. and Ansys loaddeflection curve beam (10).

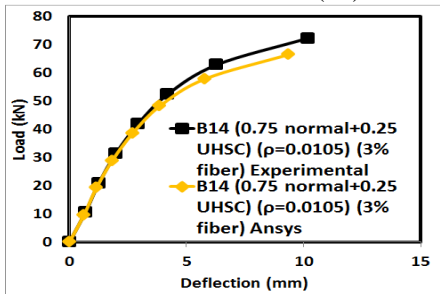

Fig. 41 Exp. and Ansys loaddeflection curve beam (14).

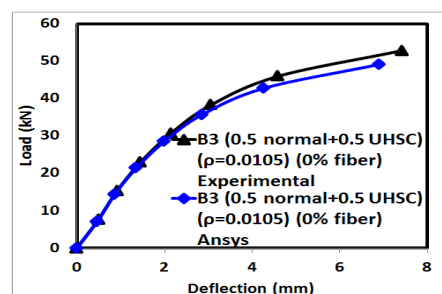

Fig. 30 Exp. and Ansys loaddeflection curve beam (3).

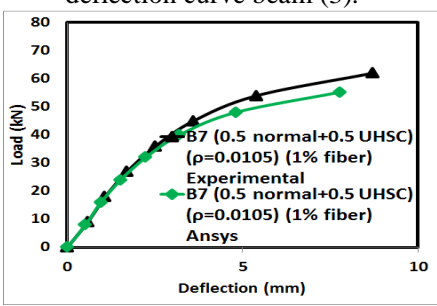

Fig. 34 Exp. and Ansys loaddeflection curve beam (7).

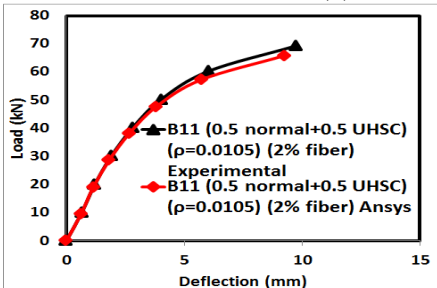

Fig. 38 Exp. and Ansys loaddeflection curve beam (11).

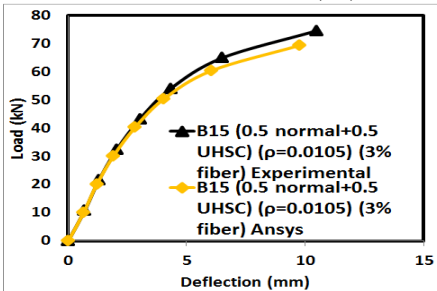

Fig. 42 Exp. and Ansys loaddeflection curve beam (15).

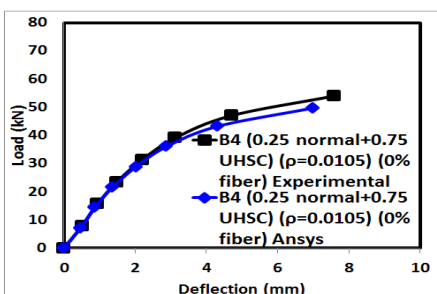

Fig. 31 Exp. and Ansys loaddeflection curve beam (4).

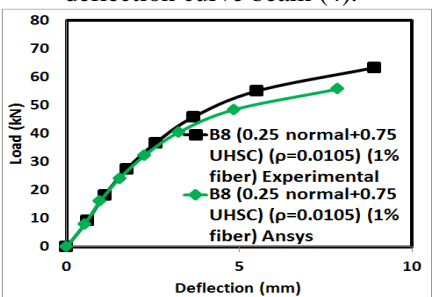

Fig.35 Exp. and Ansys loaddeflection curve beam (8).

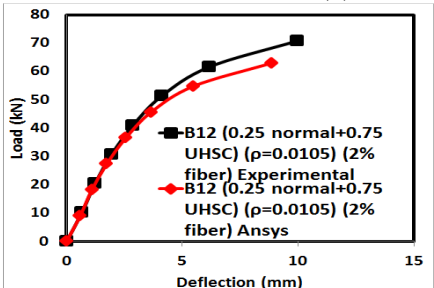

Fig. 39 Exp. and Ansys loaddeflection curve beam (12).

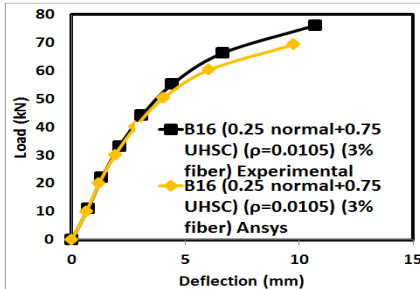

Fig. 43 Exp. and Ansys loaddeflection curve beam (16). 


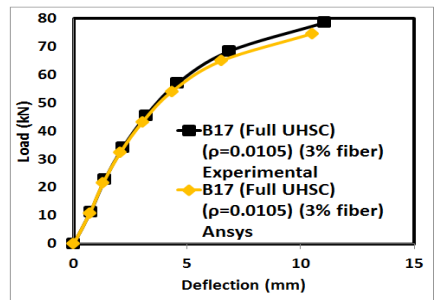

Fig. 44 Exp. and Ansys loaddeflection curve beam (17).

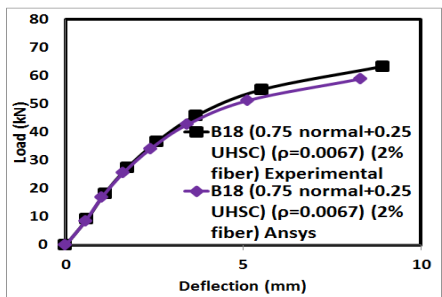

Fig. 45 Exp. and Ansys loaddeflection curve beam (18).

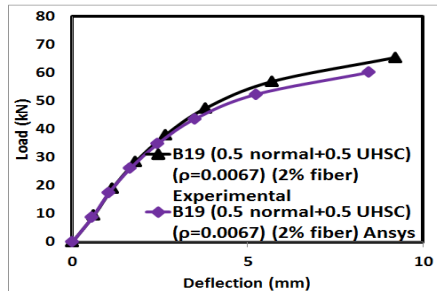

Fig. 46 Exp. and Ansys loaddeflection curve beam (19).

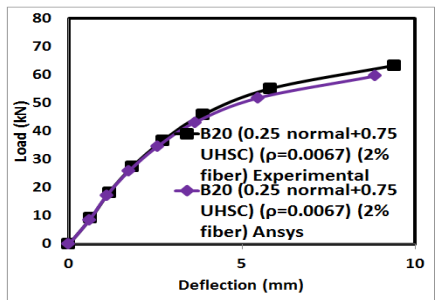

Fig. 47 Exp. and Ansys loaddeflection curve beam (20).

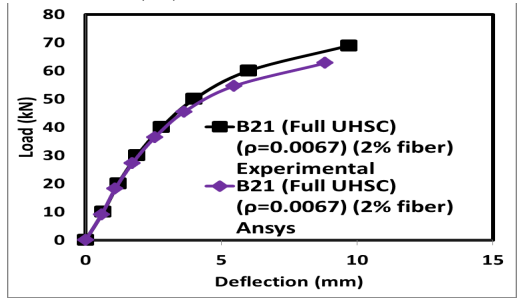

Fig. 48 Exp. and Ansys load-deflection curve beam (21).

\section{CONCLUSIONS}

The importance of the method of using two concrete types or what it called a "hybrid" for casting and its ability for replacing reinforcing ratio becomes an important issue because in civil engineering raising the compressive strength of concrete is better than in work compared to increasing the reinforcement ratio. Laboratory and theoretical work for five groups, twenty-one supported reinforced concrete beams with different reinforcement ratios cast using a hybrid concrete with two types of concrete (normal and UHSC) at different layers' depth with or without steel fibers is presented here to examine shear behavior and capacity of the reinforced concrete beams with replacing of the reinforcement ratio. Concrete hardened properties are investigated here with compressive strength, splitting tensile strength, modulus of rupture and modulus of elasticity.

Four steel fiber percentages were used here with $(0,1.0$, 2.0 and $3 \%)$. When steel fiber enhanced from $(0,1,2$ and $3 \%$ an improvement in average compressive strength, flexural strength and splitting tensile strength of about $(0$, $24.39,43.9$ and $58.53 \%),(0,78.66,132$ and $146.66 \%)$ and $(0,78.57,122.85$ and $142.85 \%)$ is achieved. Reinforced concrete beams made with normal concrete have similar behavior to that of the UHSC beams. Both have diagonal shear failures. The existence of steel fibers combined the micro-cracks and planned the crack prevalence which led to a higher maximum shear load. The lab work results showed that for $(1 \%$ steel fiber) with full layer of UHSC of beam with (reinforcement ratio $\rho=0.0105$ ) was able to give the same ultimate shear capacity and substitute for higher reinforcement ratio for normal concrete beam with (reinforcement ratio $\rho=0.0157$ ), while for ( $2 \%$ steel fiber) of beam with (reinforcement ratio $\rho=0.0105$ ) and half UHSC layer was able to give the same shear capacity loads and substitute for normal concrete beam with (reinforcement ratio $\rho=0.0157$ ). This means that the hybrid layer is an effective matter which can reduce the reinforcement ratio depends on the strength of the concrete and concrete depth. Theoretical study using FE (Ansys) program has a good compatibility that leads to saving in both time and cost compared to lab work.

\section{REFERENCES}

[1] L. G. Sorelli, A. Meda, and G. A. Plizzari, "Bending and Uniaxial Tensile Tests on Concrete Reinforced with Hybrid Steel Fibers," Journal of Material in Civil Engineering, vol. 17, no. 5, pp.519-527, 2005.

[2] O. A. Qasim, and A. S. Ahmed, "Different Variable Effects on Bond Strength of Normal, High and Ultra-High Strength Concrete International Journal of Civil Engineering and Technology, vol. 9, no. 10, pp. 1923-945, 2018.

[3] S. P. Avinash, and R. S. Parekar, "Steel fiber reinforced concrete beams under combined torsion-bending-shear," Journal of Civil Engineering (IEB), vol. 38, no. 1, pp. 31-38, 2010.

[4] O. A. Qasim, and R. Abdulsattar, "Experimental and Analytical Study of Behavior of Ultra High Self-Compacted Hollow Core Reinforced Concrete One-Way Slabs", International Journal of Applied Engineering Research, vol. 13, no. 2, pp. 1035-1055, 2018.

[5] M. Orgass, and Y. Klug, "Steel Fiber Reinforced Ultra High Strength Concretes," Institute for Structural Concrete and Building Materials, University of Leipzig, MFPA Leipzig GmbH, Lacer, no. 9, pp.12, 2004.

[6] J. Thomas, and A. Ramaswamy, "Mechanical Properties of Steel Fiber-Reinforced Concrete," Journal of Material in Civil Engineering, vol. 19, no. 5, pp.385-392, 2007.

[7] O. A. Qasim, "Comparative study between the Cost of Normal Concrete and Reactive Powder Concrete", IOP Conf. Series: Materials Science and Engineering, 2nd International Conference on Sustainable Engineering Techniques (ICSET 2019), vol. 518, $022082,2019$.

[8] J. Gustafsson, and K. Noghabai, "Steel Fibers as Shear Reinforcement in High Strength Concrete Beams," Lulea University of Technology, Division of Structural Engineering, Stockholm, Sweden, (Web Site), 2005.

[9] E. Denarie, K. Habel, and E. Bruhwiler, "Structural Behavior of Hybrid Elements with Advanced Cementitious Materials (HPFRCC)," Proceedings of $4^{\text {th }}$ International Workshop on High Performance Fiber Reinforced Cement Composites, Ann Arbor, Michigan, USA, pp. 12, 2003.

[10] K. Wille, A. E. Naaman, and G. J. Montesinos, "Ultra-HighPerformance Concrete with Compressive Strength Exceeding 150 MPa (22 ksi): A simple Way," ACI Materials Journal, vol. 108, no. 1 , pp.46-54, 2011.

[11] K. Wille, A.E. Naaman, and S. El-Tawil, "Optimizing Ultra-HighPerformance Fiber-Reinforced Concrete," Concrete International, pp.35-41, 2011.

[12] K. Habel, E. Denarie, and E. Bruhwiler, "Experimental Investigation of Composite Ultra High-Performance Fiber Reinforced Concrete and Conventional Concrete Members," ACI Structural Journal, vol. 104, no. 1, pp.93-101, 2007.

[13] K. Habel, "Structural Behavior of Elements Combining Ultra-HighPerformance Fiber Reinforced Concretes (UHPFRC) and Reinforced Concrete," Ph.D. Thesis, Ecole Polytechnique Federal De Lausanne, Switzerland, 195pp, 2004. 
[14] C. Wang, C. Yang, F. Liu, C. Wan, and X. Pu, "Preparation of UltraHigh-Performance Concrete with Common Technology of Materials," Cement and Concrete Composites, vol.34, no. 4, pp.538544, 2012.

[15] Y. L. Voo, B. Nematollahi, A. M. Said, B. A. Gopal, and T. S. Yee, "Application of Ultra High-Performance Fiber Reinforced ConcreteThe Malaysia Perspective," International Journal of Sustainable Construction Engineering and Technology, vol.3, no.1, pp.26-44, 2012.

[16] M.M. Kamal, M.A. Safan, Z.A. Etman, R.A. Salama, "Production of ultra-high-strength concrete using local materials," Engineering Research Journal, vol. 36, no. 1, pp. 91-100, 2013.

[17] B. Graybeal, "Material Property Characterization of Ultra-HighPerformance Concrete," U.S. Department of Transportation, Federal Highway Administration, Report No. FHWA-HRT-06-103, pp.176, 2006

[18] B. Graybeal, FHWA Tech Note: "Ultra High-Performance Concrete," FHWA Publication No: FHWA-HRT-11-038, Federal Highway Administration, 2011.

[19] F. Kaiss, and H. Mohammed, "Flexural Strength of Hybrid Beams Containing Reactive Powder Concrete and Conventional Concrete," Journal of Engineering and Development, vol. 18, no.5, 2014.

[20] P. Tedepalli, Y. MO, T. Hsu, and J. Vogel, "Mechanical Properties of steel Fiber Reinforced Concrete Beams," Structures Congress, ASCE, pp. 1-10, 2009.

[21] R.S. Londhe, "Experimental Investigation on Shear Strength of SFRC Beams Reinforced with Longitudinal Tension Steel Rebars," Asian Journal of Civil Engineering (Building and Housing), vol. 11, no. 3, pp. 385-395, 2010.

[22] L. Sudheer Reddy, N. V. Ramana Rao, T.D. Gunneswara Rao, "Shear Resistance of High Strength Concrete Beams Without Shear Reinforcement," International Journal of Civil and Structural Engineering, vol.1, no. 1, pp. 101-113, 2010.

[23] A. Imran Bukhari and S. Ahmed, "Evaluation of Shear Strength of High Strength Concrete Beams without Stirrups," The Arabian
Journal for Science and Engineering, vol.33, no.2B, pp.323-335, 2008.

[24] K. Noghabai, "Beams of fibrous concrete in shear and bending: experimental and model," ASCE-Journal of Structural Engineering, vol. 126, no. 2, pp. 243-251, 2000.

[25] Y. L. Voo, W. K. Poon, and Stephen J. Foster, "Shear Strength of Steel Fiber-Reinforced Ultra-High-Performance Concrete Beams without Stirrups," Journal of Structural Engineering, vol. 136, no. 11, pp. 1393-1400, 2010.

[26] O. A. Qasim, "Behavior of Reinforced Reactive Powder Concrete Two-Way Slabs with Openings", IOP Conf. Series: Materials Science and Engineering, 2nd International Conference on Sustainable Engineering Techniques (ICSET 2019), vol. 518, 022077, 2019.

[27] S. J. Foster, Y. L.Voo, and K. T. Chong, "FE Analysis of Steel Fiber Reinforced Concrete Beams Failing in Shear: Variable Engagement Model," ACI SP-237, Detroit, pp. 55-70, 2006.

[28] O. A. Qasim, "A Review Paper on Specimens Size and Shape Effects on the Concrete Properties", International Journal of Recent Advances in Science and Technology, vol. 5, no. 3, pp. 13-25, 2018.

[29] US Department of Transportation, "Silica fume user's manual", Federal Highway Administration, April, pp. 183, 2005.

[30] D. R. J. Owen and E. Hinton, "Finite Element in Plasticity: Theory and Practice", Pineridge Press, Swansea, U.K., 594 pp, 1980.

[31] O. A. Qasim, "Nonlinear Analysis of Reinforced Concrete Slabs with Openings", MS.C. Thesis, AL-Nahrain University College of Engineering, Civil Engineering Department, Iraq/ Baghdad, 2007.

[32] I. A. S. Al-Shaarbaf, "Three-Dimensional Non-linear Finite Element Analysis of Reinforced Concrete Beams in Torsion", Ph.D. Thesis, University of Bradford, U.K 323 PP, 1990.

[33] O. A. Qasim, "Behavior of Reinforced Reactive Powder Concrete Slabs with Openings", PHD. Thesis, AL-Nahrain University College of Engineering, Civil Engineering Department, Iraq /Baghdad, 2013. 